Tea Baldigara, Ph.D.

University of Rijeka, Faculty of Tourism and Hospitality Management in Opatija

UDK 338.482:330.43(497.5)

\title{
MODELLING DOMESTIC TOURISM IN CROATIA
}

Abstract: The aim of this paper is to use extrapolative modelsin the attempt to analyse and understand domestic tourism demand flows in Croatia. Such, more detailed and systematic studies should be considered as starting points of future tourism development strategies in Croatia, as a predominantly tourism oriented country. Croatian tourism is predominantly internationally oriented. Nevertheless, domestic tourism demand should be considered more exhaustively in quantitative tourism researches. The present study emphasizes the necessity of more systematic domestic tourism demand determinants quantitative analysis and researches. Econometric modelling and forecasting should be considered as a significant Croatia's tourism sector development tool. The objective of the study is therefore to examine the determinants and the functional form of domestic tourism demand in Croatia. As an approximation of domestic tourism demand, the monthly number of domestic tourist arrivals in Croatia is analysed from January 2005 to December 2017. Modelling and ex post forecasting is performed using some extrapolative models i.e. the sea-

\section{INTRODUCTION}

Tourism is the most important Croatian economic sector. Among the service industries, tourism, above all, contributes to the Croatian economic growth and development. It is a well-known fact that tourism is one of the world's leading economic activities accounting for $30 \%$ of the world's services consumption and $6 \%$ of total goods and services export (www.ira.lib.polyu.edu. $\underline{\mathrm{hk}}$ ). In Croatia, tourism is one of the most propulsive economic sectors and the driver sonal naive model, the seasonal multiplicative Holt-Winters triple exponential smoothing model, the seasonal multiplicative exponential trend model and the seasonal multiplicative integrated autoregression moving average model. Modelling the actual number of monthly domestic tourist arrivals was done for the period from January 2005 to December 2017. Based on the selected forecast models, the ex post forecast of the future value of the monthly number of domestic arrivals was made for the period from January 2018 to September 2018. The statistical diagnostic performance tests of the used models and the analysis of their prognostic efficiency showed that all the models fit well the actual data throughout the entire estimation and forecasting period.

Key Words: tourism demand, domestic tourism, monthly number of domestic tourist arrivals, the seasonal naive model, the seasonal multiplicative Holt-Winters triple exponential smoothing model, the seasonal multiplicative exponential trend model and the seasonal multiplicative integrated autoregression moving average model.

of economic growth and development. It is common knowledge that international tourism demand in Croatia is predominant with respect to domestic flows. According to the Tourist Information Service (www.turizmoteka.hr) data, in August 2018, the commercial accommodation facilities generated 4.4 million arrivals and 27.1 million tourist nights. Compared to August 2017, tourist arrivals increased by $3.9 \%$ and a slight increase in overnight stays by $0.8 \%$. Domestic tourists realized 284 thousand arrivals and 1.6 million overnight stays, an increase of $12.5 \%$ 
in arrivals and an increase in overnight stays by $8.4 \%$ as compared to August 2017. Although, Croatian tourism is predominantly international oriented, domestic tourism should be considered more exhaustively in quantitative tourism researches. Starting from the importance of tourism in the world and Croatian economy, its detailed and efficient analysis requires the implementation of specific and adequate quantitative methods in modelling and forecasting future tourist market features trends and key determinants. The enhancement of Croatian tourism competitiveness is based on a set of policy goals postulated by official institutions and bodies, i.e. to profile Croatia as one of the high-quality tourist destinations in the Mediterranean and Europe, to increase earnings by rising the spending in tourism, to extend the tourist season as well as to develop a sustainable and competitive tourism. The achievement of such and other tourism development goals necessitates a synergic action of all counterparts and stakeholders involved in the tourism sector, but above all it necessitates an accurate and combined qualitative and quantitative analysis, modelling and forecasting. (Baldigara, Mamula, 2012). Based on these premises, the paper investigates the application of time-series based quantitative methods in Croatian domestic tourism demand modelling and forecasting. Tourism demand and its characteristics, as tourism market keys determinants, are the basis for business decision making, adoption and development of business strategies in all, for tourism related, business activities and sectors of the Croatian economy. The growing interest in quantitative research on tourism demand is motivated by the rapid expansion of tourism industry all over the world. The tourism demand modelling, the analysis of economic and non-economic impacts of its determinants and the creation of efficient forecasts are the main researching issues in a large number of recent numerous discussions and studies.

\section{LITERATURE REVIEW}

Along with the growing significance of the international tourism in Croatia, it should be a growing interest in modelling and forecasting tourism demand and its components: "Modelling tourism demand in order to analyse the effects of various determinants, and accurate forecasting of future tourism demand, are two of the major focuses of tourism demand studies" (Song \& Witt, 2005).Accurate forecasts of tourism demand and its features can certainly improve planning and decision-making. Numerous studies on tourism demand modelling and forecasting have been published over the past decades. Still, according to Peng, Song and Crouch (Peng, Song, Crouch, 2014) no consensus has been reached in regards to which types of forecasting models tend to be more accurate and in which circumstances. In a comprehensive study Song and Li (2008) reviewed 121 papers on tourism demand modelling and forecasting published in the period between 2000 and 2007 and they found out that in 72 studies time-series models, were used to model or forecast tourism demand.Various versions of exponential smoothing models were used in tourism demand forecasting, but also as benchmarks in forecasting accuracy comparison. Buger, Dohnal, Katharda and Law in a study (2001) used, among others, the exponential smoothing technique in forecasting the US demand for travel to Durban, South Africa. Hue at al. (2004) used the Naïve 2 and the exponential smoothing techniques in forecasting the number of restaurants' daily customers. Law (2004) used the Naïve 2, the exponential smoothing and the trend extrapolation in forecasting hotel room occupancy rate. In the detailed outline of researches Song and Li (2008) listed 121 publications and among these there are 22 publications that used the Naïve 2, the double exponential smoothing, the moving average, the linear trend and the autoregressive method to compare forecasting accuracy. According to Song and Li (2008) "Naïve 
2 (or constant-growth rate), exponential smoothing models and simple autoregressive models have frequently appeared in the post-2000 studies, but as in earlier tourism forecasting studies, they are usually used as benchmarks for forecasting accuracy evaluation." In researching the importance of quantitative modelling, Saroja and Brinda (Saroja, Brinda, 2009) analysed and modelled monthly tourist arrivals, a time-series with strong seasonal patterns, using univariate time-series model. Although, as mentioned before, there is an increasing interest in time-series modelling and forecasting, in Croatia, there are still a lack of systematic analysis of tourism demand determinants. Profoundly aware that, modelling and forecasting tourism determinants, is a demanding issue, tourism development and economic growth should rely on accurate quantitative models and forecasts.

\section{DATA AND METHODOLOGY}

According to Song, Witt and Li (Song, Witt and Li, 2012) tourism demand is considered as the foundation on which the most of the tourism-related business decisions rest. Because of such a key role, tourism demand is considered as a determinant of business profitability, and its estimating, modelling and forecasting constitute a significant element in all planning and development strategies. In the literature traditionally, there emerge two categories of quantitative methods, the time-series models and the econometric approaches which analyse the casual relationship between the dependent and the explanatory variables. The paper researches the potentials of time-series models in analysing and researching domestic tourism demand in Croatia. Several extrapolative methods are used in the attempt to model and forecast domestic tourism demand in Croatia. In this paper, domestic tourism demand is measured in terms of the number of domestic tourists.Data are monthly, collected form the Croatian national statistical bureau and cover the period from January 2005 to September 2018.In the attempt to model and forecast domestic tourism in Croatia several extrapolative models are estimated and used for ex post tourism demand forecasting. Figure 1 shows the estimating and forecasting time horizon.

Figure 1: Estimating and ex post forecasting time horizon

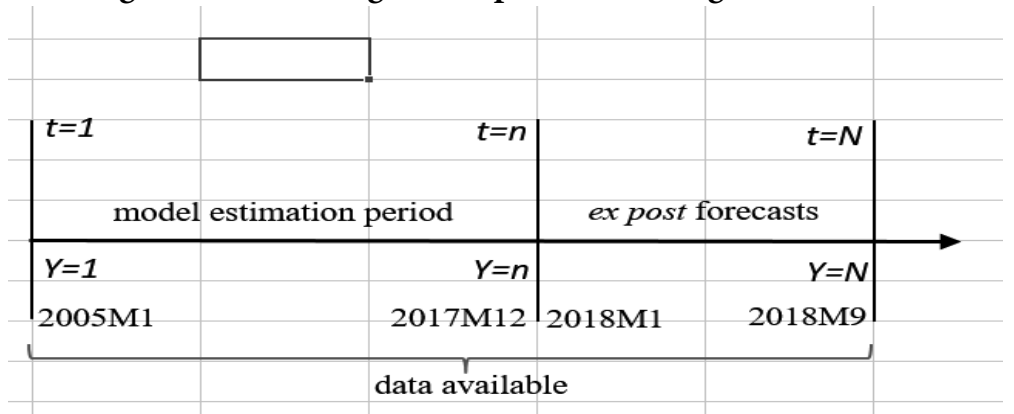

Source: Adapted from Song, H., Witt, S.F., Li, G. (2012), The Advanced Econometrics of Tourism Demand, New York, Routledge, p.183.

In Figure $1 t$ represents the time-span and $Y$ the monthly number of domestic tourist arrivals. As shown in Figure, historical data are available from January 2005 to September 2018. Tourism demand model will be estimated based on data from January 2005 to December 2017 (the sample data). Based on the estimated models, ex post forecasted will be generated from January 2018 to September 2018. For all the estimating 
and the forecast time-span all the values of the explanatory's variable and the dependent variable are known. Figure 2 shows the ac- tual data of the number of domestic tourist arrivals in the analysed period.

Figure 2: The Number of Domestic Tourist Arrivals: Time-span January 2005 to September 2018

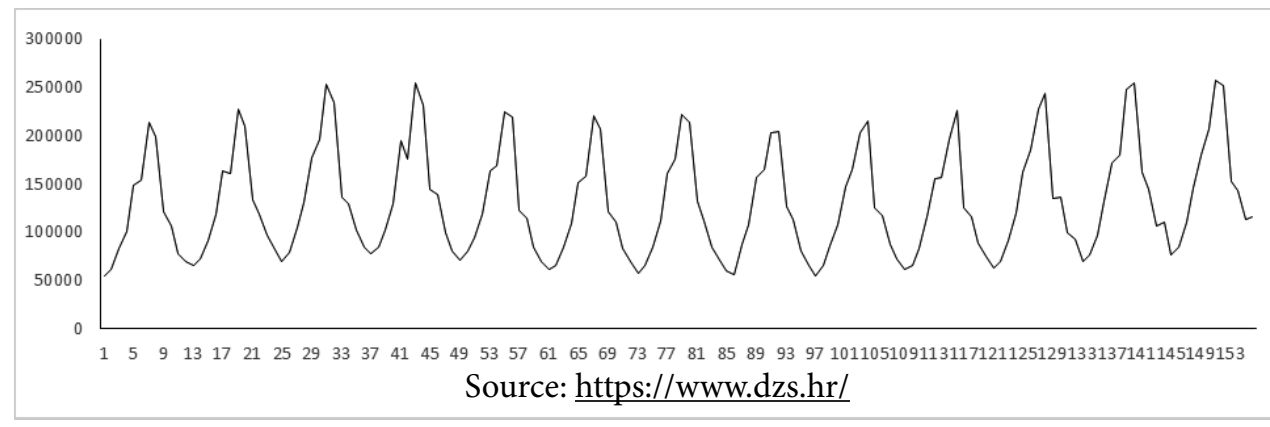

Figure 2 reveals that the time-series presents strong, seasonal influences and a slight upward trend. It is well known that tourism in Croatia is pronouncedly seasonal sensitive. In fact, the number of domestic tourists' presences is at its maximum levels in the summer period from July until August, with a drastic fall in the period from October to May. The observed time series consists of 165 observations with a mean of 130 256, 6 and a standard deviation of 55 402, 3 of domestic tourist arrivals. The maximum number of domestic arrivals was 257617 in July 2017, while the lowest number of 53 683 arrivals was realised in January 2005.It is clearly shown that the seasonal patterns are rather consistent over the analysed period. In analysing and modelling tourism demand, it is therefore important to consider its seasonal character. In literature, there are different approaches for dealing with seasonality. In this study, the-ratio-to-moving-average method, as one of the seasonal adjustment methods, is used to decompose the empirical time-series. The main purpose of the-ratio-to-moving-average method is to decompose the time-series and isolate, among the trend, the cyclical and the irregular components, the seasonal influences. In this study the multiplicative model is used (Frechtling, 2008):

$$
A_{t}=T_{t} \cdot C_{t} \cdot S_{t} \cdot I_{t}
$$

where

A - the actual value in time series

$\mathrm{T}$ - the trend component

$\mathrm{C}$ - the cyclical component

$\mathrm{S}$ - the seasonal component

I - the irregular component

$\mathrm{T}$ - some time periods less than one year ${ }^{1}$

Figure 3 shows the actual values, the seasonal adjusted values and the trend component. 


\section{Figure 3: Domestic Tourist Arrivals: Actual Values, Adjusted Time-series, Trend Component and Seasonal Factors}
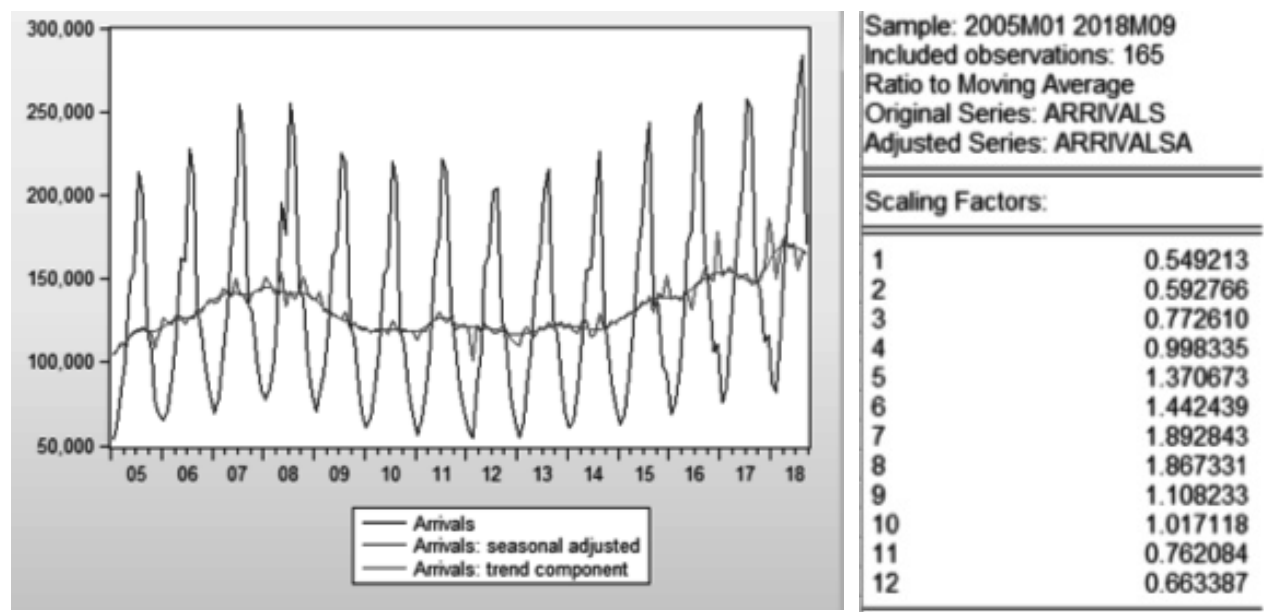

Source: EViews output

Seasonal factors show a pronounced seasonality in July and August. It is noticeable that the number of domestic tourist arrivals in July is on average higher by $89 \%$ and in August by $87 \%$ due to seasonal influences. In analysing and modelling domestic tourism demand, it is therefore important to consider its seasonal character. Therefore, specific quantitative methods that take into account this pronounced seasonal component, should be used to model the empirical time-series values. In literature, there are different approaches in dealing with seasonality. Among the different models, built to capture

$$
\begin{aligned}
& \hat{Y}_{t}=Y_{t-m} \\
& \text { where } \\
& \hat{Y} \quad=\text { forecast value } \\
& Y \quad=\text { actual value } \\
& t \quad=\text { some period time } \\
& m \quad=\text { number of periods in a year }
\end{aligned}
$$

The Naïve concepts are usually used as a benchmark forecast, namely for comparison the seasonal component, the Seasonal Naïve, the Holt-Winters, the exponential trend and the Seasonal ARIMA modelling are used in this study. The following describes the theoretical concepts of the modelling techniques adopted in this study and the essentials of the selected forecasting error to be used in evaluating the forecasting accuracy.

\section{The Seasonal Nä̈ve Model}

The seasonal naive model is used with seasonal data and postulates that the next period's value is equal to the value of the same period in the previous year. The seasonal naive model is expressed as follows: with the forecast generated by other more sophisticated forecasting methods. 
The Multiplicative Seasonal Holt-Winters

Model

The Holt-Winters' trend and seasonality method employs triple exponential smoothing: one equation for the level, one for the trend and one for the seasonality. The following equations are associated with all the named elements ${ }^{2}$ :

Level:

$$
L_{t}=\alpha \cdot \frac{Y_{t}}{S_{t-s}}+(1-\alpha)\left(L_{t-1}+b_{t-1}\right)
$$

Trend:

$$
b_{t}=\beta\left(L_{t}-L_{t-1}\right)+(1-\beta) b_{t-1}
$$

Seasonal:

$$
S_{t}=\gamma \frac{Y_{t}}{L_{t}}+(1-\gamma) S_{t-s}
$$

Forecast:

$$
F_{t+h}=\left(L_{t}+h b_{t}\right) S_{t-s+h}
$$

where

$L \quad=$ level of the series

$\alpha \quad=$ level smoothing constant between 0 and 1

$Y_{t} \quad=$ actual value

$s \quad=$ number of seasonal periods in a year

$b \quad=$ trend of the series

$\beta=$ seasonal smoothing constant between 0 and 1

$S \quad=$ seasonal component

$\gamma \quad=$ seasonal smoothing constant between 0 and 1

$t=$ some period time

$h \quad=$ number of time periods ahead to be forecast

The initialization, as the process of providing a forecast value for the first period, can be approached using the following equations:

Initial level:

$$
L_{s}=\frac{Y_{1}+Y_{2}+\cdots+Y_{s}}{s}
$$

Initial trend:

$$
b_{s}=\frac{1}{S}\left(\frac{Y_{s+1}-Y_{1}}{S}+\frac{Y_{s+2}-Y_{2}}{S}+\cdots+\frac{Y_{s+s}-Y_{s}}{S}\right)
$$

Seasonal indices for the first year:

$$
S_{1}=\frac{Y_{1}}{L_{s}}, S_{2}=\frac{Y_{2}}{L_{s}}, \ldots, S_{s} \frac{Y_{s}}{L_{s}}
$$

2 Adapted from Frechtling, D. C. (2008), Forecasting Tourism Demand: Methods and Strategies, Butterworth Heinemann, Oxford, pp. 95-97. 
Alternatively, the initial level, initial trend and the seasonal factors can be obtained by fitting a least squares trend line of the historical data.

\section{Multiplicative Seasonal Exponential Trend Model}

In the attempt to model time-series with a pronounced seasonal pattern the exponential trend model is usually used:

$$
\begin{aligned}
& Y_{t}=\beta_{0} \cdot \beta_{1}{ }^{x} \cdot \varepsilon_{t} \\
& \text { where } \\
& Y_{t} \quad=\text { actual value of the series in period } t \\
& x_{t}=\text { assigned time value in period } t \\
& \varepsilon_{t}=\text { term error in period } t
\end{aligned}
$$

The multiplicative model is suitable for modelling when the amplitude of seasonal variations decreases or increases proportionally over time, which is the characteristic of many economic time-series. If the seasonal component is constant through the whole period, seasonality can be removed by adding seasonal dummy variables. When analysing seasonal time-series with monthly data, equation (9) is modified and adjusted to fit the actual data pattern:

$$
Y_{t}=\beta_{0} \beta_{1}^{x_{t}} \beta_{2}^{M_{1}} \beta_{3}^{M_{2}} \beta_{4}^{M_{3}} \beta_{5}^{M_{4}} \beta_{6}^{M_{5}} \beta_{7}^{M_{6}} \beta_{8}^{M_{7}} \beta_{9}^{M_{8}} \beta_{10}^{M_{9}} \beta_{11}^{M_{10}} \beta_{12}^{M_{11}}
$$

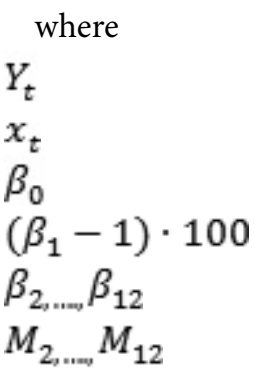

$$
\begin{aligned}
& =\text { actual value of the series in period } t \\
& =\text { time } \\
& =\text { constant } \\
& =\text { average monthly growth rate } \\
& =\text { monthly multiplier compared to base month } \\
& =\text { seasonal dummy variables taking a value of } 1 \text { in the relevant } \\
& \text { month and } 0 \text { otherwise }
\end{aligned}
$$

In model (11) the intercept term is included and the number of dummy variables is once smaller than the number of unit time intervals. The lack of modelling tourism demand with this model is reflected in its very assumptions, namely the deterministic character of the trend and seasonal variations. Namely, the seasonal component is usually not deterministic and independent of other non-seasonal components. It is most commonly stochastic and correlates with other non-seasonal components present in the time series. Models that describe such processes are defined as ARIMA models.

The Multiplicative Seasonal Autoregressive Integrated Moving Average Model

Seasonal Autoregressive Integrated Moving Average (SARIMA) processes are used in modelling time series with trend components and seasonal patterns. They have been developed from the standard model of Box and Jenkins (1970) and incorporate both 
seasonal autoregressive and moving average factors into the modelling process. In order to deal with seasonality, ARIMA processes have been modified and adjusted and SARIMA models have then been formulated. The seasonal ARIMA (the SARIMA) models incorporate both non-seasonal and seasonal factors in a multiplicative model as follows (Baldigara, Mamula, 2012):

$$
\operatorname{ARIMA}(p, d, q) \times(P, D, Q) S
$$

where:

$p=$ non-seasonal AR order

$d=$ non-seasonal differencing

$q=$ non-seasonal MA order

$P=$ seasonal AR order

$D=$ seasonal differencing

$Q=$ seasonal MA order

$S=$ time span of repeating seasonal pattern

The seasonal autoregressive integrated moving average model of Box and Jenkins (1970) is given by

$$
\phi(B) \Phi\left(B^{s}\right)(1-B)^{d}\left(1-B^{s}\right)^{D} Y_{t}=\Theta_{0}+\theta(B) \Theta\left(B^{s}\right) \varepsilon_{t}
$$

where

$$
\begin{array}{lcc}
\phi(B) & =1-\emptyset_{1} B-\emptyset_{2} B^{2}-\cdots-\emptyset_{p} B^{p} \quad \text { is the } p \text {-order non seasonal AR model } \\
\theta(B) & =1-\theta_{1} B-\theta_{2} B^{2}-\cdots-\theta_{q} B^{q} \quad \text { is the } q \text {-order non seasonal MA model } \\
\Phi\left(B^{s}\right) & =1-\Phi_{1} B^{s}-\Phi_{2} B^{2 s}-\cdots-\Phi_{P} B^{P_{s}} \quad \text { is the } P \text {-order seasonal AR model } \\
\Theta\left(B^{s}\right) & =1-\Theta_{1} B^{s}-\Theta_{2} B^{2 s}-\cdots-\Phi_{Q} B^{Q s} \quad \text { is the } Q \text {-order seasonal MA model } \\
(1-B)^{d} & \text { denotes the non-seasonal differencing of order d } \\
\left(1-B^{s}\right)^{D} & \quad \text { denotes the seasonal differencing of order D } \\
\varepsilon_{t} & \text { is the error term } \sim \mathrm{IID}\left(0, \sigma^{2}\right) \\
B & \text { is the backward shift } \\
S & \text { is the seasonal order }
\end{array}
$$

\section{Model Performance and Forecast Accuracy}

Forecast model performances and accuracy is evaluated using some chosen prognostic errors as forecast accuracy measures. According to Frechling (Frechtling, 2001) "the most familiar concept of forecasting accuracy is called "error magnitude accuracy", and relates to forecast error associated with a particular forecasting model." The error magnitude is defined as:

$$
e_{t}=A_{t}-F_{t}
$$

where

$t \quad=$ some time period

$e \quad=$ forecast error

$A \quad=$ actual value of the variable being forecast

$F \quad=$ forecast value 
Among the different methods developed to measure the error magnitude accuracy this paper will consider the Mean Absolute Error (MAE), the Root Mean Square Error (RMSE) and the Mean Absolute Percentage Error (MAPE). The following describes the basic concepts of the different forecast accuracy measures used in this paper.

$$
M A E=\frac{1}{n} \sum_{t=1}^{n}\left|\left(A_{t}-F_{t}\right)\right|
$$

The smaller the value of MAE is, the more accurate is the forecast.

The Root Mean Square Error (RMSE) is computed by the following expression:

$$
R M S E=\sqrt{\frac{1}{n} \sum_{t=1}^{n}\left(A_{t}-F_{t}\right)^{2}}
$$

For purpose of communicating results, it is usually best to report the Root Mean Square Error (RMSE) rather than MSE, because the RMSE is measured in the same units as the data, rather than in squared units, and is representative of a "typical" error (Nau, 2013). The RMSE is usually more sensitive than other forecast accura- cy measures. RMSE and MAE can only be compared between models whose errors are measured in the same units.

The Mean Absolute Percentage Error (MAPE) is expressed in generic percentage terms and it is computed by the following formula:

$$
M A P E=\frac{1}{n} \sum_{t=1}^{n} \frac{\left|\left(A_{t}-F_{t}\right)\right|}{A_{t}} \cdot 100
$$

MAPE is a simple measure that permits to compare the accuracy of different models, with different time periods and numbers of observations.

\section{EMPIRICAL RESULTS AND ANALYSIS}

The following reports the results of the estimated extrapolative models and the ex post forecasting results.

\section{Seasonal Nä̈ve Model}

The Seasonal Naive model was defined under the assumption that the number of monthly domestic tourist arrivals at time $t$ was the same as the value at time $t-12$. The model was estimated using actual data from January 2005 to December 2017. The ex post forecast was generated using data from January 2018 to September 2018. Results are show in the nest figure. 
Figure4: Actual andEstimated Number of Monthly Domestic Tourist Arrivals: Time Span: 2005M1-2017M12 and Forecast 2018M1-2018M9

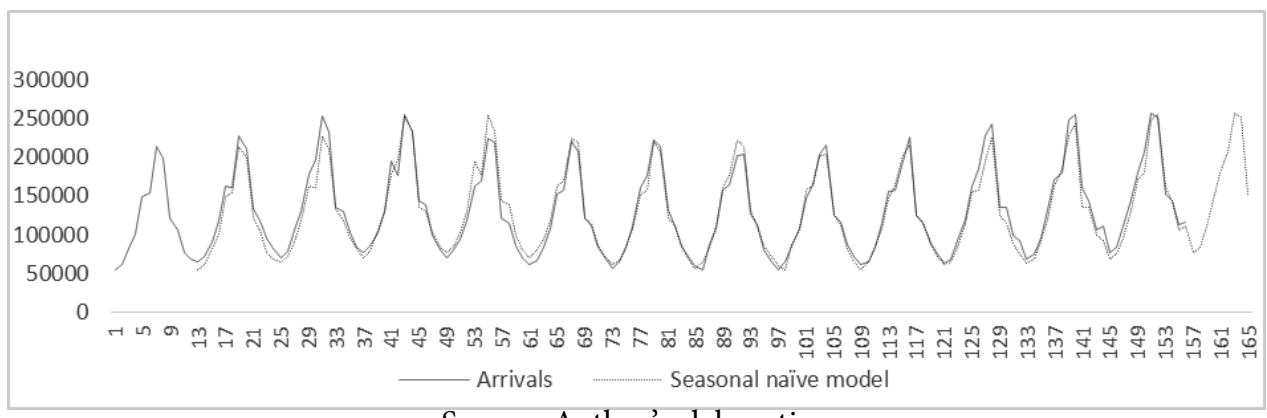

Source: Author's elaboration

As shown in figure 4 the estimated seacasting the number of monthly domestic sonal naïve model fits the data reasonably tourist arrivals. In the multiplicative model, well throughout the entire estimating time period.

Triple Exponential Holt-Winters Model

The multiplicative seasonal Holt-Winit is assumed that each observation is the product of a non-seasonal value and a seasonal index for that particular period.Analters model was used in modelling and fore-

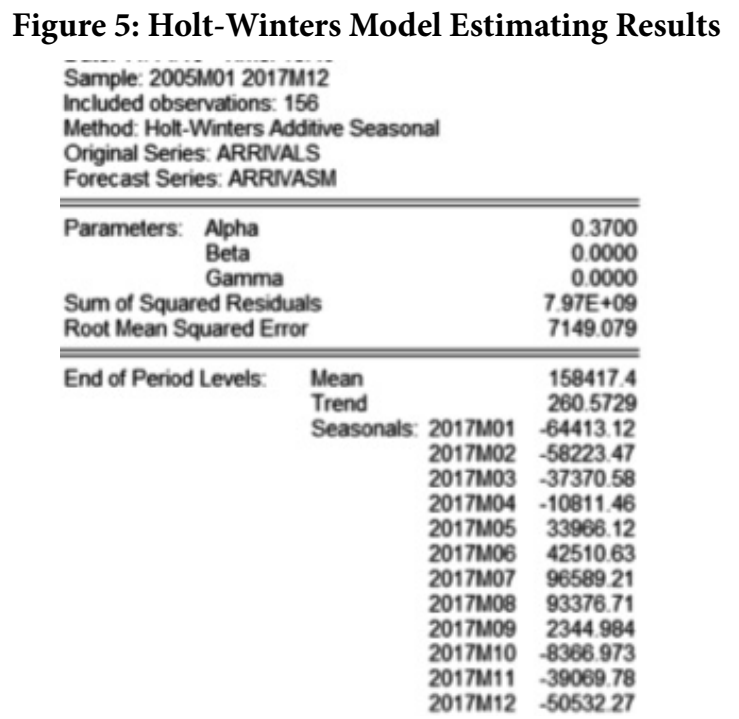

Source: Eviewsoutput

The smoothing process resulted in three smoothing constants: $\alpha=0,37, \beta=0,0$ and $\gamma=0,0$. Values of zero for the level and trend component smoothing constant indicate that the trend and seasonal component are estimated as fixed for the entire period, and not changing. According to Lee, Song and Mjelde (Lee, Song, Mjelde, 2008) a value of 0,5 for the smoothing constant $\alpha$ indicates that the current single smoothed values were 
predicted based on the moderate weight on both current values adjusted for seasonality and previous values smoothed and trend values. The smoothing constant $\beta=0$ implies that the current trend values are a function of the previous trend values without considering the difference in the smoothed values. The smoothing constant $\gamma=0$ denotes that the current seasonal component is a function of the previous seasonal without considering the current values to be adjusted by the smoothed values. The following picture shows the original series of monthly domestic tourist arrivals and the forecast obtained with the seasonal multiplicative Holt-Winters model.

Figure6: Actual and Estimated Number of Monthly Domestic Tourist Arrivals: Time Span: 2005M1-2017M12 and Forecast 2018M1-2018M9

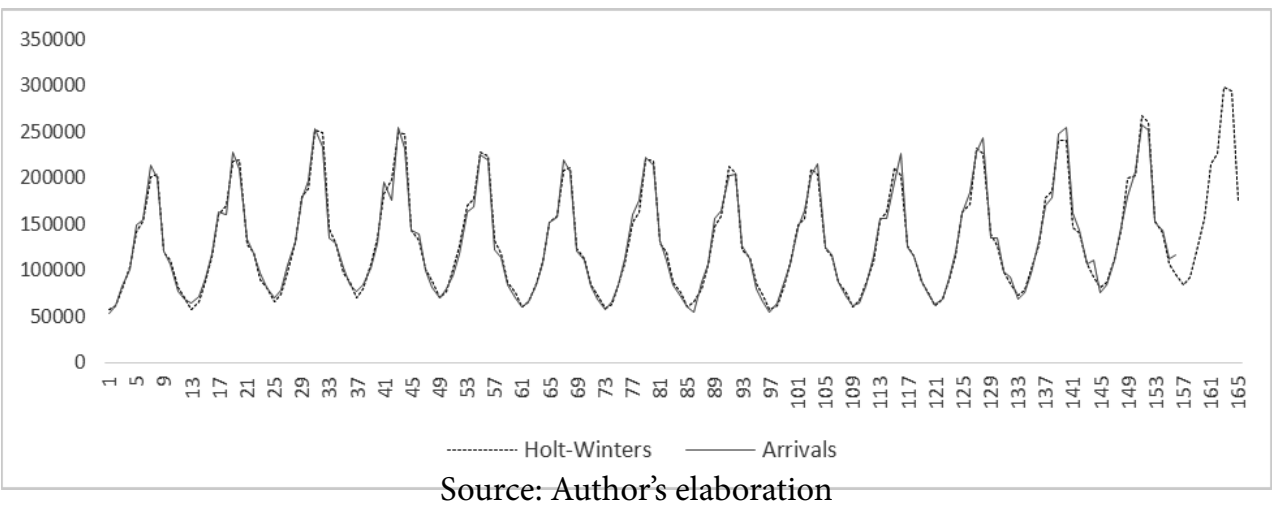

Seasonal Multiplicative Exponential Trend Model

The regression model of the monthly series of domestic tourist arrivals with exponential trend and seasonal dummy variables given in equation (11) is linearized (using logarithms) and estimated using the least squares method. December 2017is selected as the benchmark month. The linearized model is given by the following expression:

$$
\begin{gathered}
\ln \hat{Y}=\ln \beta_{o}+X_{t} \ln \beta_{1}+M_{1 t} \ln \beta_{2}+M_{2 t} \ln \beta_{3}+M_{3 t} \ln \beta_{4}+M_{4 t} \ln \beta_{5}+M_{5 t} \ln \beta_{6}+M_{6 t} \ln \beta_{7}+M_{7 t} \ln \beta_{8} \\
+M_{8 t} \ln \beta_{9}+M_{9 t} \ln \beta_{10}+M_{10 t} \ln \beta_{11}+M_{11 t} \ln \beta_{12}
\end{gathered}
$$

Regression analysis results are given in the following output. 
Figure 7: Regression analysis output

\begin{tabular}{|c|c|c|c|c|}
\hline \multicolumn{5}{|c|}{$\begin{array}{l}\text { Dependent Variable: LNARRNALS } \\
\text { Method: Least Squares } \\
\text { Date: } 11 / 21 / 18 \text { Time: } 12.02 \\
\text { Sample: } 2005 M 012017 \mathrm{M} 12 \\
\text { Included observations: } 156\end{array}$} \\
\hline Variable & Coefficient & Std. Error & t-Statistic & Prob. \\
\hline C & 11.22503 & 0.033424 & 335.8343 & 0.0000 \\
\hline TME & 0.000745 & 0.000189 & 3.941203 & 0.0001 \\
\hline M1 & -0.212780 & 0.041643 & -5.109595 & 0.0000 \\
\hline M2 & -0.119637 & 0.041634 & -2.873533 & 0.0047 \\
\hline M3 & 0.143977 & 0.041626 & 3.458825 & 0.0007 \\
\hline M4 & 0.398347 & 0.041619 & 9.571341 & 0.0000 \\
\hline M5 & 0.721000 & 0.041612 & 17.32659 & 0.0000 \\
\hline M6 & 0.771951 & 0.041607 & 18.55350 & 0.0000 \\
\hline M7 & 1.044773 & 0.041602 & 25.11352 & 0.0000 \\
\hline M8 & 1.031833 & 0.041598 & 24.80478 & 0.0000 \\
\hline M9 & 0.510761 & 0.041595 & 12.27935 & 0.0000 \\
\hline M10 & 0.426799 & 0.041593 & 10.26131 & 0.0000 \\
\hline M11 & 0.140135 & 0.041592 & 3.369307 & 0.0010 \\
\hline R-squared & 0.942503 & \multicolumn{2}{|c|}{ Mean dependent var } & 11.68829 \\
\hline Adjusted R-squared & 0.937678 & \multicolumn{2}{|c|}{ S.D. dependent var } & 0.424755 \\
\hline S.E. of regression & 0.106037 & \multicolumn{2}{|c|}{ Akaike info criterion } & -1.570395 \\
\hline Sum squared resid & 1.607881 & \multicolumn{2}{|c|}{ Schwarz criterion } & -1.316241 \\
\hline Log likelihood & 135.4908 & \multirow{2}{*}{\multicolumn{2}{|c|}{ Hannan-Quinn criter. }} & -1.467169 \\
\hline F-statistic & 195.3408 & & & 0.359609 \\
\hline Prob(F-statistic) & 0.000000 & \multicolumn{2}{|c|}{ Durbin-Watson stat } & \\
\hline
\end{tabular}

Source: EViews output

According to Šošić (Šošić, 2004) the sea- from the results of the F-test. All estimated sonal effect of the first month is contained in the constant. The value of the adjusted R-squared coefficient (93.7\%) indicates a high accuracy of the trend, as can be seen regression coefficients are significant at the level of $5 \%$. In table 1 , the original values of the estimated regression coefficients are given.

Table 1: Values of the Estimated Regression Coefficients

Regression coefficients

$\beta_{0}$ : constant

$\beta_{1}$ : the slope for the time interval (month)

$\beta_{2}$ :January

$\beta_{3}:$ February

$\beta_{4}:$ March

$\beta_{5}$ : April

$\beta_{6}$ : May

$\beta_{7}$ : June

$\beta_{8}$ : July

$\beta_{9}$ : August

$\beta_{10}$ : September

$\beta_{11}$ : October

$\beta_{12}$ : November

$$
\ln \beta_{i} \quad \beta_{i}=e^{\ln \beta_{i}}
$$

$11,19591 \quad 72831,74$

$0,001092 \quad 1,001093$

$-0,19279 \quad 0,824652$

$-0,11172 \quad 0,894298$

$0,159088 \quad 1,172441$

$0,419364 \quad 1,520993$

$0,731194 \quad 2,07756$

$0,789446 \quad 2,202175$

$1,050642 \quad 2,859485$

$1,043748 \quad 2,839841$

$0,522946 \quad 1,68699$

$0,427492 \quad 1,533407$

$0,140482 \quad 1,150828$

Source: Elaborated by author 
The constant $\beta_{0}=74984$ represents the value of the monthly number of domestic tourist arrivals in the first month (January 2017). The actual number of monthly domestic arrivals in January 2017 was 53,683. The difference shows a residual of 21,301 monthly domestic arrivals. Since the trend presents covariation in terms of average, its accuracy can be evaluated using the standard deviation and the coefficient of variation. The standard deviation of the trend is
0.415020 , that is, the average deviation of the actual monthly number of domestic arrivals from the trend values. The relative amount is $3.54 \%$, which indicates good fit of the trend. The values of the estimated seasonaldummy variables for each month indicate the average change in the number of domestic arrivals for the unit time change.The average monthly growth rate of the observed time series is derived from the value of the regression coefficient

$$
\beta_{1}:\left(\beta_{1}-1\right) \cdot 100=(1,001093-1) \cdot 100=0,1093 \%
$$

The number of domestic tourist arrivals in the observed period grew by $0.1 \%$ on average. The obtained values of estimated coefficients represent monthly growth rates relative to the benchmark month and point to the conclusions that, due to seasonal influences, during:

- January there are on average $17.53 \%$ less domestic tourist arrivals than in December;

- February there are on average $10.57 \%$ of domestic tourist arrivals less than in December;

- March there are on average $17.24 \%$ of domestic tourist arrivals more than in December;

- April there are on average $52.09 \%$ of domestic tourist arrivals more than in December;

- May there are on average $107.76 \%$ of domestic tourist arrivalsmore than in December;

- June there are on average $120.22 \%$ of domestic tourist arrivals more than in December;

- July there are on average $185.95 \%$ of domestic tourist arrivals more than in December;

- August there are on average $183.98 \%$ of domestic tourist arrivals more than in December;

- September there are on average $68.69 \%$ of domestic tourist arrivals more than in December;

- October there are on average $53.34 \%$ of domestic tourist arrivals more than in December and

- November there are on average $15.08 \%$ of domestic tourist arrivals more than in December.

Diagnostic tests of the estimated model showed good results. The analysis of resid- uals indicates that they are normally distributed (Figure 8).

\section{Figure 8: Distribution of the Residuals}

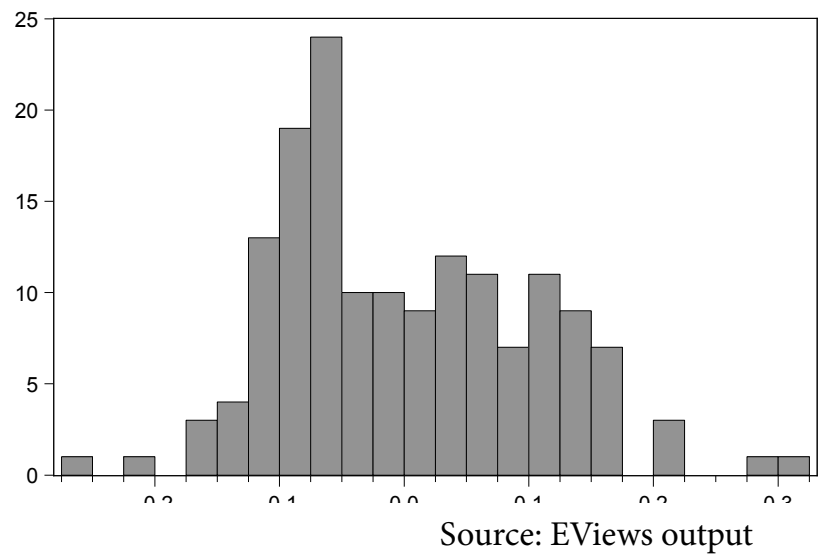

\begin{tabular}{lr} 
Series: Residuals \\
Sample 2005M01 2017M1: \\
Observations & 156 \\
& \\
Mean & $-4.80 \mathrm{e}-17$ \\
Median & -0.019597 \\
Maximum & 0.321914 \\
Minimum & -0.250980 \\
Std. Dev. & 0.101850 \\
Skewness & 0.450665 \\
Kurtosis & 2.800226 \\
& \\
Jarque-Bera & 5.539984 \\
Probability & 0.062662 \\
\hline
\end{tabular}

Source: EViews output 
The next Figure shows the actual number of domestic tourist arrivals, the estimated number and the ex post forecast generated using the seasonal multiplicative exponential trend model.

\section{Figure 9: Actual and Estimated Number of Monthly Domestic Tourist Arrivals: Time Span: 2005M1-2017M12 and Forecast 2018M1-2018M9}

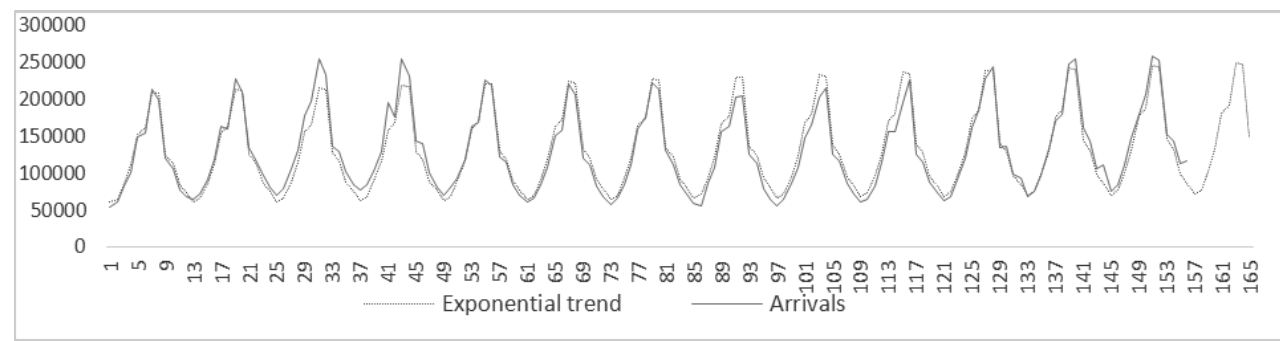

Source: Author's elaboration

Seasonal multiplicative ARIMA model

The plotting of the empirical time-series of the monthly number of domestic tourist arrivals indicates a slight and continuous upward trend after 2011. Stationarity ADF testing (Figure 10) has shown that the time series is seasonally integrated $(1,12)$.

Figure 10: ADF Test Results

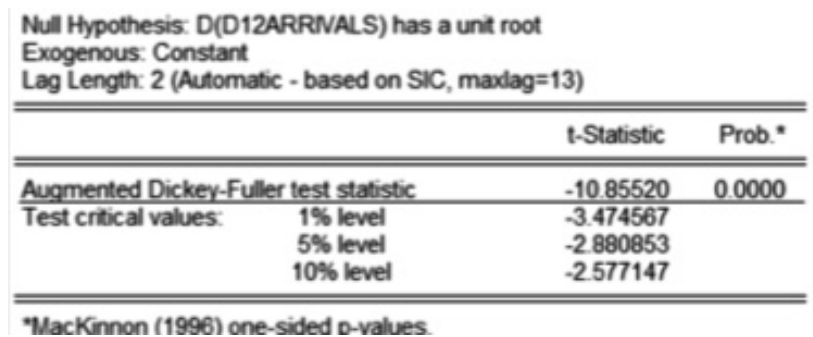

Source: EViews output

Various models were generated and among them the seasonal $(0,1,1)$ $(0,1,1)_{12}$ ARIMA model was selected. In fact, this model presented the smallest AIC, SBC and HQ Information criterion and the smallest mean absolute percentage error. In the model the constant term was not included since the mean of the differentiated time series with the standard deviation of
10194, 99 results in the standard error of $\operatorname{se}(\bar{z})=\frac{\hat{\sigma}}{\sqrt{n}}=\frac{10194,99}{\sqrt{152}}=833,68$ and the ratio $\bar{z}=45,32237 \quad \operatorname{se}(\bar{z})=\frac{\hat{\sigma}}{\sqrt{n}}=\frac{10194,99}{\sqrt{152}}=833,68$ indicating that the constant term is not statistically significant and does not need to be included in the model. The estimation results of the selected model are reported in the next table. 
Figure 11: Parameter Estimation Results for the Selected Seasonal $(0,1,1)(0,1,1)_{\mathrm{x} 12}$ ARIMA Model

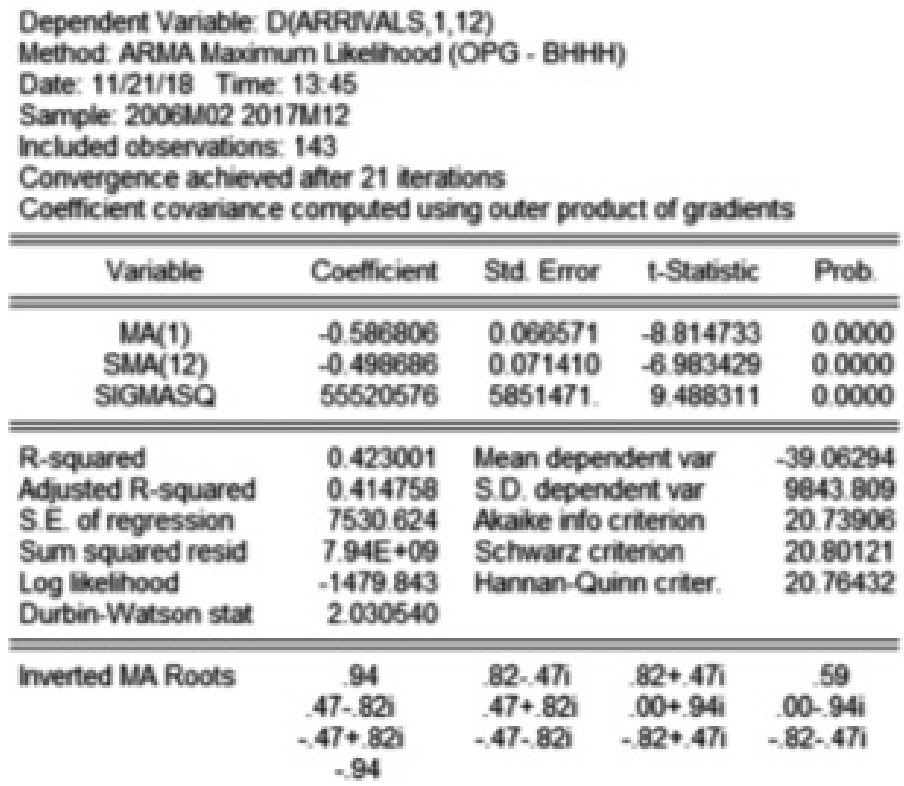

Source: EViews output

The parameter of the estimated model The selected model is tested for invertibility are all significant at 5\% level and the adjust- by using the inverted AR/MA roots. The reed $\mathrm{R}^{2}$ of 0,42 shows a quite good model fit. sults are shown in the figure below.

\section{Figure 12:Invertibility Results Testing}
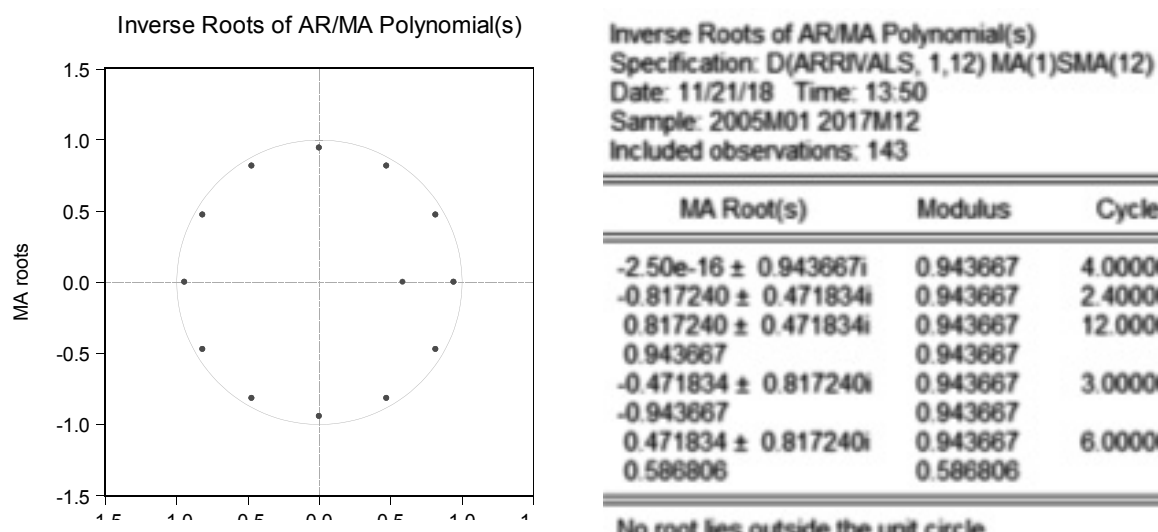

\begin{tabular}{ccc}
\hline \hline MARoot(s) & Modulus & Cycle \\
\hline \hline$-2.50 \mathrm{e}-16 \pm 0.943667 \mathrm{i}$ & 0.943667 & 4.000000 \\
$-0.817240 \pm 0.471834 \mathrm{i}$ & 0.943667 & 2.400000 \\
$0.817240 \pm 0.471834 i$ & 0.943667 & 12.00000 \\
0.943687 & 0.943667 & \\
$-0.471834 \pm 0.817240 \mathrm{i}$ & 0.943667 & 3.000000 \\
-0.943667 & 0.943667 & \\
$0.471834 \pm 0.817240 \mathrm{i}$ & 0.943667 & 6.000000 \\
0.586806 & 0.586806 & \\
\hline \hline
\end{tabular}

No root lies outside the unit circle. ARMA model is invertible. 
As reported in Figure 12 all the absolute values of the inverted MA roots are smaller than one, the estimated model is therefore invertible. The selected multiplicative seasonal integrated autoregressive moving av- erage model passes all the diagnostic tests. In fact, testing results showed that the residuals are normally distributed and not correlated (figure 13).

Figure 13: Residuals Results Testing for the Selected Seasonal ARIMA Mode 1

\begin{tabular}{|c|c|c|c|c|c|}
\hline Autocorrelation & Partial Correlation & $A C$ & PAC & Q-Stat & Prob \\
\hline 11 & 10 & $1-0.019$ & -0.019 & 0.0545 & \\
\hline 1$\} 1$ & $1\} 1$ & 20.039 & 0.039 & 02818 & \\
\hline 111 & 111 & $3-0.023$ & -0.022 & 0.3599 & 0.549 \\
\hline 1$] 1$ & $1] 1$ & 40.014 & 0.011 & 0.3881 & 0.824 \\
\hline idi & idi & $5-0.035$ & .0033 & 0.5720 & 0903 \\
\hline id, & 111 & $6-0.037$ & -0.040 & 0.7805 & 0.941 \\
\hline 111 & 10 & 7.0 .029 & .0028 & 09106 & 0.969 \\
\hline 1d & 1d 1 & $8-0.095$ & -0.096 & 23018 & 0.890 \\
\hline $1 \mathrm{p}$ & 17 & 90.111 & 0.110 & 4.1977 & 0.757 \\
\hline $1 \sqrt{1}$ & $1 \sqrt{1}$ & $10-0.011$ & -0.002 & 42152 & 0.837 \\
\hline i l & $1 \mathrm{~g}$ & 110.103 & 0.091 & 5.8809 & 0.752 \\
\hline $1 \sqrt{1}$ & $1 \sqrt{1}$ & $12-0.013$ & -0.007 & 5.9097 & 0.823 \\
\hline
\end{tabular}

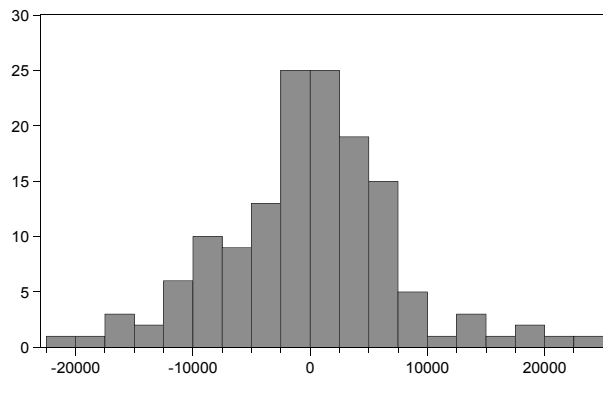

Series: Residuals

Sample 2006M02 2017M1 Observations 143

Mean $\quad-89.64600$

Median $\quad 148.7435$

Maximum $\quad 22665.21$

Minimum $\quad-20813.23$

Std. Dev. $\quad 7476.862$

Skewness $\quad 0.116166$

Kurtosis $\quad 3.874459$

Source: EViews output

All the autocorrelation coefficients do not differ significantly from zero and they are within the 2-sigma limits $\left( \pm 2 \cdot \frac{1}{\sqrt{n}}\right)$ and there is no evidence of autocorrelation of residuals. Moreover, the residuals are normallydistributed. The actual time series of the monthly number of domestic arrivals, the estimated value obtained using the seasonal multiplicative ARIMA model $(0,1,1)(2,1$, 2) 12 , and the series of residual deviations, are shown below.

\section{Figure 14: Actual, Estimated Number of Monthly Domestic Tourist Arrivals}

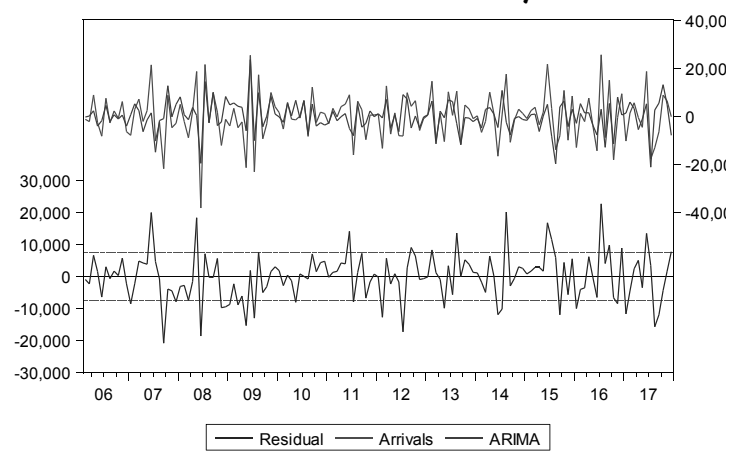

Source: EViews output 
The results confirm the correct specification of the model.

Forecast Accuracy of the Estimated Extrapolative Models

The models used to analyse the monthly number of domestic tourist arrivals fit the general movement of the analysed series during the entire sample period. The empirical results are reasonably good. The forecasted values, in fact, are quite close to the actual values. The actual number of monthly domestic tourist arrivals and the forecasted values are shown in the following table.

Table2: Actual and Forecasted Values

\begin{tabular}{|l|r|r|r|r|r|}
\hline & Actual number & $\begin{array}{c}\text { Seasonal } \\
\text { Nä̈ve } \\
\text { model }\end{array}$ & $\begin{array}{c}\text { Holt-Winters } \\
\text { model }\end{array}$ & $\begin{array}{c}\text { Exponential trend } \\
\text { model }\end{array}$ & ARIMA model \\
\hline 2018MI & 87973 & 76040 & 84630,93 & 71292,04 & 86197,24 \\
\hline $2018 \mathrm{M} 2$ & 82011 & 84378 & 92986,29 & 77397,52 & 93331,5 \\
\hline $2018 \mathrm{M} 3$ & 118715 & 110553 & 120838,7 & 101580,8 & 114221,6 \\
\hline $2018 \mathrm{M} 4$ & 167231 & 146113 & 155832,6 & 131923,8 & 149915,6 \\
\hline $2018 \mathrm{M} 5$ & 199562 & 179948 & 215364,8 & 180394,2 & 188399,9 \\
\hline $2018 \mathrm{M} 6$ & 233896 & 207001 & 226694 & 191422,8 & 195829,5 \\
\hline $2018 \mathrm{M} 7$ & 262573 & 257617 & 297811,8 & 248831,2 & 263506,3 \\
\hline $2018 \mathrm{M} 8$ & 283678 & 252217 & 294047,3 & 247392,1 & 265534,9 \\
\hline $2018 \mathrm{M} 9$ & 170058 & 151809 & 174688,2 & 147122,4 & 174915,6 \\
\hline
\end{tabular}

Source: Elaborated by author

The forecasting results are plotted as showed in Figure 15.

\section{Figure 15: Actual and Forecasted Values of the Number of Monthly Domestic Tourist Arrivals from 2018M01 to 2018M09}

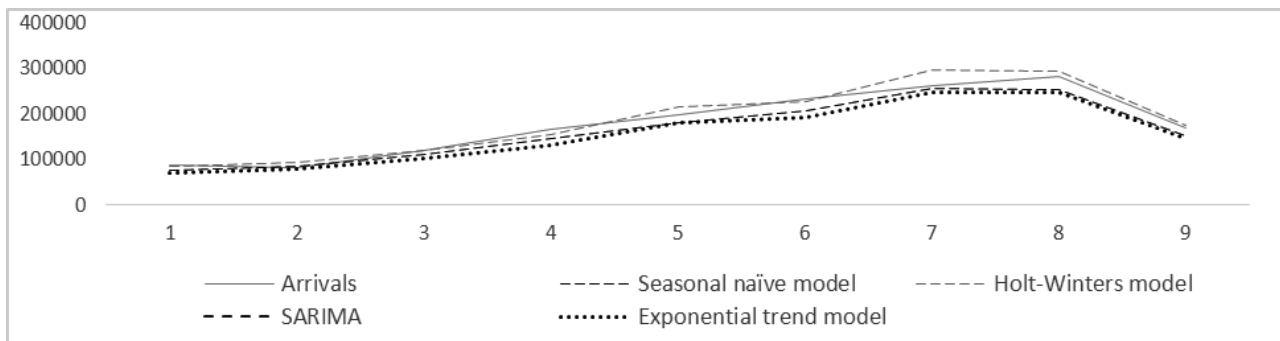

Source: Elaborated by author

The conducted diagnostic tests showed that all selected models describe and forecast the time series of monthly domestic tourist arrivals reasonably well. The forecasting accuracy is evaluated using the previously mentioned forecast errors.

Table 16: Forecasting Accuracy Evaluation

\begin{tabular}{|l|r|r|r|}
\hline Model & \multicolumn{1}{|l|}{ MAE } & \multicolumn{1}{l|}{ MAPE } & \multicolumn{1}{l|}{ RMSE } \\
\hline Seasonal Naïve Model & 9264,23 & 7,35 & 11892,42 \\
\hline Holt-Winters Model & 5257,24 & 4,08 & 4832,93 \\
\hline Exponential Trend Model & 1,09513 & 2,18 & 1,114944 \\
\hline SARIMA Model & 13069,16 & 6,94 & 16953,52 \\
\hline
\end{tabular}

Source: Elaborated by author 
The results indicate that the Holt-Winters Model and the Exponential Trend Model generated the most accurate forecasts, although all the estimated models present a reasonably good forecasting accuracy.

\section{CONCLUSIONS}

The aim of the paper was to model and forecast domestic tourist demand in Croatia. Although Croatia's tourism is primarily of international character, in recent years, domestic tourism has become an increasingly important andsignificant source of income. As an approximation of the domestic tourism demand, the monthly number of domestic tourist arrivals in Croatia is analysed in the period from January 2005 to September 2018. Modelling and ex post forecasting was performed using extrapolative models, i.e. the seasonal naive model, the seasonal multiplicative Holt-Winters model, the seasonal multiplicative exponential trend model and the seasonal multiplicative integrated autoregressionmoving average model. The estimation span-time referred to the period from January 2005 to December 2017 and ex post forecasts were generated for the period from January 2018 to September 2018. The statistical diagnostic performance tests and the forecast accuracy evaluation confirmed that models well describe the actual data throughout the entire estimation period, but also over the forecasting time period. Profoundly aware that modelling tourism demand is a challenging and controversial issue, that the adequacy of a forecasting model is valued according to its out-of-sample forecasts as well as that it is still difficult to indicate which model or class of models is more adequate for tourism demand modelling, the author of this study wished to highlight the necessity of more systematic quantitative analysis of Croatia's tourism demand in all its determinants.

\section{BIBLIOGRAFY}

Baldigara, T. (2013) Forecasting Tourism Demand in Croatia: A Comparison of Different Extrapolative Methods. Journal of Business Administration Research, Vol. 2, No.1. pp. 84-92.

Baldigara, T. and Mamula, M. (2015) International tourism demand modelling: A multivariate approach, International Journal of Research in Commerce, IT \& Management 5, no. 02:1-7. ISSN 2231-5756

Baldigara, T. and Mamula, M. (2012), Tourism Demand Modelling and Forecasting-A Case Study of Croatia, In: 6th International Conference of the School of Economics and Business Beyond the Economic Crisis: Lessons Learned and Challenges Ahead, ICES 2012, University of Sarajevo, School of Economics and Business, 12-13 October 2012, Sarajevo, Bosnia and Herzegovina, pp. 906-921.

Baldigara, T. and Mamula, M. (2013) Dealing with seasonality: Modelling tourism demand in Croatia. International Journal of Research in Commerce, Economics \& Management, Vol. 3 No. 11, pp.23-29.

Baldigara, T. and Mamula, M. (2015) International tourism demand modelling: A multivariate approach. International Journal of Research in Commerce, IT \& Management, Vol. 5 No. 02, pp. 1-7.

Baldigara, T. and Mamula, M. (2015) Modelling international tourism demand using seasonal ARIMA models" Tourism and Hospitality Management 21, no. 1:19-33. ISSN 1330-7533.

Baldigara, T. and Mamula, M. (2015) Modelling international tourism demand using seasonal ARIMA models. Tourism and Hospitality Management, Vol 21 No. 1, pp. 19-33.

Baldigara, T., Koić, M. (2015) Modelling Occupancy Rates in Croatian Hotel Industry. International Journal of Business Administration, Vol. 6. No. 3, pp. 121-131.

Chang, C., Sriboonichtta, S., \&Wiboobpongse, A. (2009) Modelling and 
forecasting tourism from East Asia to Thailand under temporal and spatial aggregation. Mathematics and Computers in Simulation, 79 (5): 1730-1744.

Chang, Y.W. and Liao M.Y. (2010) A seasonal ARIMA model of tourism forecasting: The case of Taiwan. Asia Pacific Journal of Tourism Research, Vol. 15, No. 2, pp. 215-221.

Cho, V. (2003) A comparison of three different approaches to tourist arrival forecasting, Tourism Management, 24(3): 323-330.

Chu, F.L. (2009) Forecasting tourism demand with ARIMA-based methods. Tourism Management, 30 (5): 740-751.

Claveira, O. and Torra, S. (2014) Forecasting tourism demand to Catalonia: Neural networks vs. Time series models. Economic Modelling, Vol. 36, pp. 220-228.

Coshall, J.T. and Charlesworth, R. (2011) A management oriented approach to combination forecasting of tourism demand. Tourism Management, Vol. 32, No. 4, pp. 759-769.

Dobre, I., \&Alexandru, A.A. (2008) Modelling unemployment rate using Box-Jenkins procedure, Journal of applied quantitative methods, 3(2): 156-166.

Fernandes, P., Teixeira, J., Ferreira, J.M., \&Azevedo, S.G. (2008) Modelling Tourism Demand: A Comparative Study between Artificial Neural Networks and the Box-Jenkins Methodology. Romanian Journal of Economic Forecasting, 9(3): 30-50.

Folgieri, R., Baldigara, T. and Mamula, M. (2017) Artificial neural networks-based econometric models for tourism demand forecasting. In: 4th International Scientific Conference Tourism and Creative Industries: Trends and Challenge.Opatija, Hrvatska: Fakultetzamenadžment u turizmuiugostiteljstvu. pp. 169-182.

Frechtling, D.C. (2001) Forecasting Tourism Demand: Methods and Strategies. Woburn: Butterworth Heinemann, Elseivier plc group.
Gunter, U. and Önder, I. (2015) Forecasting international city tourism demand for Paris: Accuracy of uni- and multivariate models employing monthly data. Tourism Management, Vol. 46, pp. 123-135.

KanTsui, W.H., Bali, H.O., Gilbey, A. and Gow, H. (2014) Forecasting of Hong Kong airport's passenger throughput. Tourism Management, Vol. 42, pp. 62-76.

Lee, C.K., Song, H.J., \&Mjelde, J.W. (2008) The forecasting of International Expo tourism using quantitative and qualitative techniques. Tourism Management, 29 (6): 1084-1098.

Lim, C. \& Pan, G.W. (2005) Inbound tourism developments and patterns in China. Mathematics and Computers in Simulation, 68 (5-6): 499-507.

Lim, C.andMcAleer, M. (2002), "Time series forecast of international travel demand for Australia. Tourism Management, Vol. 22, pp. 389-396.

Lin, C.J., Chen, H.F. and Lee, T.S. (2011) Forecasting Tourism Demand Using Time Series, Artificial Neural Network and Multivariate Adaptive Regression Splines: Evidence from Taiwan. International Journal of Business Administration, Vol. 2, No. 2, pp.14-24.

Loganathan, N., andYahaya, I. (2010) Forecasting International Tourism Demand in Malaysia Using Box-Jenkins SARIMA Application. South Asian Journal of Tourism and Heritage, 3(2): 55-70.

Peng, B., Song, H. and Crouch, B. (2014) A meta-analysis of international tourism demand forecasting and implications for practice. Tourism Management, Vol. 45, pp.181-193.

Selvanathan, S. andViswanathan, B. (2009) Modelling the domestic and foreign tourist arrivals to Tamil Nadu (India). Applied Economics, Taylor \& Francis Journals, vol. 41(24), pages 3131-3142.

Shen, S., Li, G. and Song, H. (2011) Combination Forecasts of International Tourism Demand, Annals of Tourism Research, (38)1: 72-89. 
Shen, S., Li, G. and Song, H. (2009) Effect of seasonality treatment on the forecasting performance of tourism demand models. Tourism Economics, pp. 693-708.

Song, H. and Li, G. (2008) Tourism demand modelling and forecasting $-\mathrm{A}$ review if recent research. Tourism Management, Vol. 29, No. 2, pp. 203-220.
Song, H., Witt, S. \& Gang, L. 2012, The Advanced Econometrics of Tourism Demand, Routledge, London.

Wong, K.F. and Song, H. (2007) Tourism forecasting: To combine or not to combine? Tourism Management, Vol. 28, No. 4, pp. 1068-1078. 